\title{
Organochloride Pesticides and Polychlorinated Biphenyls in Human Breast Milk: Case Study in the Suburbs of Hue City, Vietnam
}

\author{
Nguyen Van Hop ${ }^{1, ~ *, ~ V u ~ T h i ~ K i m ~ L o a n ~}{ }^{2}$, Thuy Chau To ${ }^{3}$ \\ ${ }^{1}$ Faculty of Chemistry, Hue University of Sciences, Hue city, Vietnam \\ ${ }^{2}$ Department of Chemistry, Hai Phong University of Medicine and Pharmacy, Hai Phong city, Vietnam \\ ${ }^{3}$ Faculty of Resources and Environment, Thu Dau Mot University, Thu Dau Mot city, Vietnam \\ Email address: \\ ngvanhopkh@gmail.com (N. V. Hop)
}

\section{To cite this article:}

Nguyen Van Hop, Vu Thi Kim Loan, Thuy Chau To. Organochloride Pesticides and Polychlorinated Biphenyls in Human Breast Milk: Case Study in the Suburbs of Hue City, Vietnam. International Journal of Science, Technology and Society. Vol. 3, No. 4, 2015 , pp. 151-155. doi: $10.11648 /$ j.ijsts.20150304.18

\begin{abstract}
Organochlorine pesticides (OCPs, including DDTs and HCHs) and polychlorinated biphenyls (PCBs) were detected in 64 human breast milk samples collected from lactating mothers living in three communes and two wards in the suburbs of Hue city, Central Vietnam in 2010 and in 2011. Assessment of health risk for breast fed babies was conducted, basing on estimation of estimated daily intake (EDI) of the pollutants (OCPs and PCBs) by the babies and then comparing with tolerable daily intake (according to the guideline of Canada Health Agency). The results obtained showed that the EDIs were much lower than the TDIs.
\end{abstract}

Keywords: OCPs, PCBs, Breast Milk, Hue City

\section{Introduction}

Diclodiphenyltricloetans (DDTs) and hexacloxyclohexans (HCHs) were two of the widely-used organochlorine pesticides (OCPs) in Vietnam since 1960s. The OPCs and polychlorinated biphenyls (PCBs) (used as transformer oil) belong to 12 persistent organic pollutants (POPs), which are the most dangerous chemicals for environment and human health (Polder A., 2009; Sudaryanto A., 2006, Devanathan G, 2009). For recent years, many places of remains of useprohibited and/or use-expiry date OCPs were found in many provinces/cities in Vietnam. 28 sites of pesticides remains were found in the rural and urban areas in Hue city of Thua Thien Hue province in 2004. The remains of pesticides estimated was $3,140 \mathrm{~kg}$, of which OCPs, phosphorous pesticides and others occupied $17 \%, 18 \%$ and $65 \%$, respectively (Hung N.V., 2005). OCPs and PCBs collection and treatment after use-expiry date in Vietnam was not tightly regulated and controled. These raised much concern about scatter of the OCPs and PCBs into environment (water, soil, sediment and air) and adverse effect on human health. A study on the levels of DDTs and HCHs in soil samples collected in distance of $50-100 \mathrm{~m}$ from the OCPs remain sites showed that (Hung N.V., 2005): i) DDTs level in the 14 of 20 soil samples were higher than the requirement of Vietnam regulation TCVN 5941-1995 (100 ppb): in the range of $120-470 \mathrm{ppb}$; ii) HCHs levels in the 12 of 20 soil samples were higher than that of the regulation (100 ppb): in the range of $110-500 \mathrm{ppb}$.

The researches on the OPCs in Tam Giang - Cau Hai lagoon in Thua Thien Hue province, a biggest lagoon in South East Asia, going along the sea with the area of 22,000 ha and receiving river waters from the land and sea water through two inlets (Thuan An and Tu Hien inlets), showed that:

- DDTs content in the lagoon sediment (based on dry weight) was in the range of $9.8-33.4 \mathrm{ppb}(\mathrm{n}=27$ in year 2001; Khoa N.X., 2004) and $0.2-8.2 \mathrm{ppb}(\mathrm{n}=10$ in 2005; Thi T.T.V., 2007); the DDTs levels were higher than that specified in the ISQG, Canada $(4.48 \mathrm{ppb})$ and many data in Khoa's study were even higher than the PEL, Canada (16.32 ppb) applied to marine sediment;

- HCHs content in the lagoon sediment (ranging from 5.6 to $92.4 \mathrm{ppb} ; \mathrm{n}=10$ in 2005; Thi T.T.V., 2007) was 6 to 90 times higher than that of the PEL (0.99 ppb); several levels of aldrin and dieldrin observed by Thi's study in 
the lagoon ( $\mathrm{n}=10$ in 2005) were 5 to 30 times higher than that of the PEL (4.30 ppb); also, levels of endrin found in several samples $(\mathrm{n}=10$ in 2005) were about 10 times higher than that of the ISQG $(2.67 \mathrm{ppb})$, but lower than that of the PEL (62.4 ppb).

The high levels of OCPs in the lagoon sediment are likely to be adversely affecting the ecosystem, human health via food chains and the quality and productivity of aquatic biota in the lagoon. High bioaccumulation of DDTs in several benthic species was found in the period 1998 to 2001 in rabbitfish (mean $\pm \mathrm{S}=179 \pm 52 \mathrm{ppb} ; \mathrm{n}=25$ ) and local carp $(286 \pm 82 \mathrm{ppb} ; \mathrm{n}=25)$ collected in the Tam Giang - Cau Hai lagoon. The levels of DDTs and HCHs found in bivalve (Meretrix meretrix) collected from Thuan An area in the lagoon were in the range of $34-53 \mathrm{ppb}$ and $5-7 \mathrm{ppb}$, respectively (Sy H.T., 2008). Although these were preliminary studies only, there should certainly be concerns about the quality of aquatic products as well as the human health implications of consuming them.

As use of OCPs in agriculture has been prohibited in Vietnam since 1995, a decreasing trend in the OCPs level in the lagoon water and sediment can be observed from the above data: decrease in DDTs level from 9.8 - $33.4 \mathrm{ppb}$ in 2001 down to $0.2-8.2 \mathrm{ppb}$ in 2005. In spite of that, DDTs are still being used for malaria prevention and illegally for agricultural purposes by many local farmers due to entrenched habits and the high effectiveness of DDTs. As such, concerns about the adverse effects on organisms and human health remain.

Many current studies confirmed that mothers with contact or without contact with OPCs had excess of DDTs and HCHs in their breast milk (Raab U. et al., 2008, Wang Y. R., 2008). DDTs \& HCHs are called endocrine disruptors. They and PCBs are accumulated in fatty tissue of human and excreted through breast milk. Their excretion is very slow. Therefore, breast milk is used as bio-monitoring matter to assess the accumulation of DDTs, HCHs and PCBs in human (Ennaceur S. et al., 2008; Minh N. H. et al., 2004). As a result of this, the hazardous chemicals can be estimated in breast-fed babies. High content of OCPs and PCBs in breast milk may negatively affect the development of breast fed babies, disorder endocrine and resist estrogen (Polder A. et al., 2009, Ntow W. J., 2008, Kunisue T., 2006). Therefore, content of OCPs and PCBs in breast milk are one of good indicators to assess human health risk. In term of lactating mothers, the content of OCPs and PCBs in breast milk is the relationship with many factors such as age of mother, the number of their children, food, content of lipid in their body and other environmental factors.

There were many researches on assessing the accumulation of OCPs and PCBs in environment as well as the analyzing and evaluating their presence in breast milk with the aim at defining the origin of morbidity and fatality in human by these chemicals. However, the study on this problem is still a few in Vietnam generally and in Hue city particularly. This study was conducted with the aim of assessing levels of DDTs (p,p'-DDE; o,p'-DDT and p, $\mathrm{p}^{\prime}$
DDT), HCHs (-HCH, - $\mathrm{HCH}$ and $-\mathrm{HCH})$ and PCBs (PCB 28, $52,101,118,138,153$ and 180) in breast milk collected from lactating mothers in the suburbs of Hue city.

\section{Methods}

Human breast milk samples were randomly collected from 30 lactating farmer mothers and from 10 lactating nonfarmers mothers (with average age of 26 - 29, range of 18 40) living in three suburb communes of Hue city: Thuy Xuan (n 13), Huong Long (n 13) and Thuy duong (n 14) in 2010. Also, breast milk samples were collected from 24 lactating non-farmer mothers in the two wards of Hue city in 2011: Thuy Bieu (n 14) and An Cuu (n 14) (Fig.1). The samples were stored at $4^{\circ} \mathrm{C}$ at sampling sites and at $-20^{\circ} \mathrm{C}$ in laboratory prior to analysis.

Sample extraction was conducted as follows (Minh N.H., 2004; Raab U., 2008, Beyer A., 2010): $10 \mathrm{~g}$ of the breast milk sample was added onto $10 \mathrm{~g}$ pre-cleaned diatomite earth (Merck, Damstadt, Germany) packed in a glass column and then chemicals to be analyzed were extracted with $200 \mathrm{~mL}$ diethyl ether at a flow rate of $1 \mathrm{~mL} / \mathrm{min}$. The extract was concentrated to $8 \mathrm{~mL}$ by vacuum evaporator. One-fifth of the concentrated extract was used for fat content determination by gravimetric method. The remaining extract was purified on chromatogaphic mini-column packed with $2 \mathrm{~g}$ activated florisil (Florisil 30 - 60 mesg, Sigma - Aldrich, USA) and 1 $\mathrm{cm}$ length of activated anhydrous sodium sulfate (Merck, Germany) top side. The lipid in the purified-extract was removed by concentrated sulfuric acid treatment (Merck, Germany). The lipid-removed extract was evaporated to 1 $\mathrm{mL}$ under a gentle stream of nitrogen and was ready for gas chromatographic analysis.

The separation and detection of DDTs, HCHs and PCBs was performed by gas chromatography system (Agilent 7890 A) equipped with an auto-injection system (Agilent 7683B), micro-electron capture detector ( $\mu$-ECD) and HP5-MS capillary column (5\% phenyl methyl siloxane phase, $30 \mathrm{~m} \mathrm{x}$ $0,25 \mathrm{~mm}$ i.d. $\mathrm{x} 0,25 \mu \mathrm{m}$ film thickness). Nitrogen was used as gas carrier at a flow rate of $1.5 \mathrm{~mL} / \mathrm{min}$ and make-up gas in the detector at $5 \mathrm{~mL} / \mathrm{min}$. $1 \mu \mathrm{L}$ of the final extract was injected into injector operated at $285^{\circ} \mathrm{C}$ and splitless mode. The temperature of the detector was $300^{\circ} \mathrm{C}$. The column oven temperature was programmed from $90^{\circ} \mathrm{C}$ (held for $2 \mathrm{~min}$ ) to $150^{\circ} \mathrm{C}$ at a rate of $30^{\circ} \mathrm{C} / \mathrm{min}$, to $204^{\circ} \mathrm{C}$ (held for $3 \mathrm{~min}$ ) at a rate of $3^{\circ} \mathrm{C} / \mathrm{min}$, and finally to $280^{\circ} \mathrm{C}$ (held for $10 \mathrm{~min}$ ) at a rate of $8^{0} \mathrm{C} / \mathrm{min}$; quantification was made by calibration curve method (Alvarez, M.F., 2008; Burke E.R., 2003; Minh T.B., 2003).

A $1000 \mathrm{ppb}$ standard solution of the three-isomer DDTs (Accustandard, USA), a $1000 \mathrm{ppb}$ solution of the threeisomer HCHs (Accustandard, USA) and a 7-congener standard solution of PCBs (PCB 28, 52, 101, 118, 138, 153 and 180) - PCBs standard "Mix 3" (Dr. Ehrenstorger, Germany) with 10 ppm concentration of each congener were used for preparation of working standard solutions.

Quality control of the gas chromatographic analysis with 
micro-electron capture detector (GC/ $\mu$-ECD) was done:

- 0.5 - $100 \mathrm{ppb}$ multi-level calibration curves of the OCPs and PCBs were created for quantification with good linearity $(r>0.99)$;

- The method limit of detection (LOD) for the chemicals to be analyzed $(\mathrm{LOD}=3 \mathrm{~S}$; $\mathrm{S}$ calculated from the data of analysis of the chemicals with concentration of each $0.5 \mathrm{ppb} ; \mathrm{n}=9$ ) were $0.02-0.04 \mathrm{ppb}$ for DDTs, $0.01-$ $0.06 \mathrm{ppb}$ for HCHs and $0.01-0.05 \mathrm{ppb}$ for PCBs;

- The repeatability of analysis of two levels of each chemical (5 ppb and $50 \mathrm{ppb}$ standard solutions) was good: $\mathrm{RSD}=2.3-2.9 \%$ and $0.4-7.9 \%(\mathrm{n}=3)$ for DDTs; RSD $=0.4-3.0 \%$ and $0.4-0.7 \%(\mathrm{n}=3)$ for $\mathrm{HCH}$ and $\mathrm{RSD}=2.0-4.0 \%$ and $0.2-0.5 \%(\mathrm{n}=3)$ for PCBs;

- The method accuracy was good for analysis of a practical breast milk sample spiked with $29.4 \mathrm{ng} / \mathrm{g}$ lipid each chemical: recoveries for DDTs, HCHs and PCBs were $115-146 \%, 89-132 \%$ and $80-138 \%$, respectively.

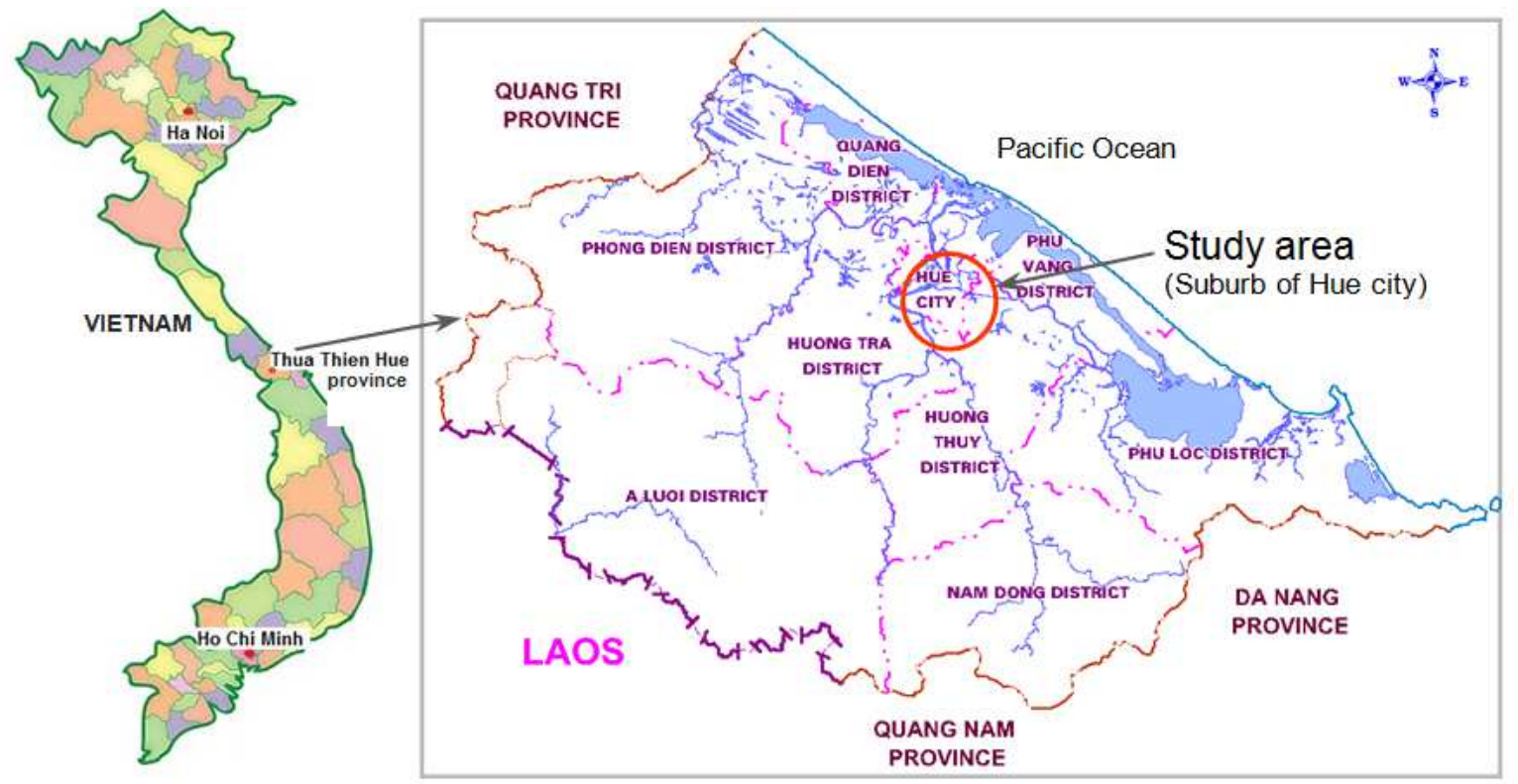

Fig. 1. Study area in the suburb of Hue city in Thua Thien Hue province.

\section{Results and Discussion}

The results of analysis of OCPs and PCBs in the breast milk samples showed in Table 1 and Table 2.

Table 1. Levels (ng/g lipid) of OCPs and PCBs in the human breast milk samples in three communes in the suburb area of Hue city in 2010 ${ }^{(*)}$.

\begin{tabular}{|c|c|c|c|c|c|c|c|c|}
\hline \multirow{2}{*}{ Chemical } & \multicolumn{2}{|c|}{ Thuy Xuan $(n=13)$} & \multicolumn{2}{|c|}{ Huong Long $(n=13)$} & \multicolumn{2}{|c|}{ Thuy Duong $(n=14)$} & \multicolumn{2}{|c|}{ Overall $(n=40)$} \\
\hline & Mean & Range & Mean & Range & Mean & Range & Mean & Range \\
\hline Lipids \% & 1.6 & $0.8-3.8$ & 1.8 & $0.4-6.3$ & 2.8 & $0.8-6.1$ & 2.1 & $0.4-6.3$ \\
\hline p,p'-DDE & 52.9 & $2.3-130$ & 42.6 & $5.4-100$ & 25.4 & $6.3-67.7$ & 40.3 & $2.3-130$ \\
\hline o,p'-DDT & 7.9 & $1.8-15$ & 15 & $2.0-31$ & 11.3 & $2.3-18$ & 11.4 & $2.0-31$ \\
\hline p,p'-DDT & 28.6 & $0.8-91$ & 48.4 & $7.7-202$ & 28.7 & $1.3-86$ & 35.2 & $0.8-202$ \\
\hline DDTs & 89.4 & $4.9-171$ & 106 & $18.1-284$ & 65.4 & $22.7-130$ & 86.9 & $18.1-284$ \\
\hline$\alpha-\mathrm{HCH}$ & 21.2 & $7.0-34$ & 32.8 & $4.2-104$ & 15.9 & $4.4-38$ & 23.3 & $4.2-104$ \\
\hline$-\mathrm{HCH}$ & 22.3 & $3.5-68$ & 24.5 & $3.0-103$ & 20.4 & $4.1-97$ & 22.4 & $3.0-103$ \\
\hline$-\mathrm{HCH}$ & 33.0 & $10.0-59$ & 41.4 & $6.1-107$ & 22.6 & $6.3-54$ & 32.3 & $6.1-107$ \\
\hline $\mathrm{HCHs}$ & 76.5 & $20.5-149$ & 98.7 & $13.3-248$ & 58.9 & $27.0-189$ & 78.0 & $13.3-248$ \\
\hline PCB 28 & $<\mathrm{LOD}$ & n.d. & $<\mathrm{LOD}$ & n.d. & 1.0 & $<$ LOD -1.0 & 0.3 & $<$ LOD-1.0 \\
\hline PCB 52 & 65 & $<$ LOD -65 & 40 & $<\mathrm{LOD}-70$ & 24 & $<\mathrm{LOD}-24$ & 43 & $<\mathrm{LOD}-70$ \\
\hline PCB 101 & $<\mathrm{LOD}$ & n.d. & $<\mathrm{LOD}$ & n.d. & 1.2 & $<\mathrm{LOD}-1.2$ & 0.4 & $<$ LOD -1.2 \\
\hline PCB 118 & $<\mathrm{LOD}$ & n.d. & 0.5 & $<$ LOD -0.5 & 16 & $<$ LOD - 32 & 5.5 & $<$ LOD - 32 \\
\hline PCB 138 & $<\mathrm{LOD}$ & n.d. & $<\mathrm{LOD}$ & n.d. & 0.7 & $<\mathrm{LOD}-0.8$ & 0.2 & $<$ LOD -0.8 \\
\hline PCB 180 & 13 & $0.7-27$ & 14 & $0.7-27$ & 19 & $5.3-48$ & 15 & $0.7-48$ \\
\hline PCBs & 78 & $0.7-92$ & 55 & $1.0-98$ & 63 & $5.3-109$ & 65 & $0.7-108$ \\
\hline
\end{tabular}

(*) LOD was $0.02 \mathrm{ppb}$ for PCB 28, 0.02 ppb for PCB 52, $0.01 \mathrm{ppb}$ for PCB 101, 0.04 ppb for PCB 118, 0.03 ppb for PCB 153, 0.03 ppb for PCB 138 and 0.05 ppb for PCB 180; n.d.: no determined 
Table 2. Levels (ng/g lipid) of OCPs and PCBs in the human breast milk samples in two wards in the suburb area of Hue city in $2011^{(*)}$.

\begin{tabular}{|c|c|c|c|c|c|c|}
\hline \multirow{2}{*}{ Chemical } & \multicolumn{2}{|c|}{ Thuy Bieu $(n=14)$} & \multicolumn{2}{|c|}{ An Cuu $(n=14)$} & \multicolumn{2}{|c|}{ Overall $(n=28)$} \\
\hline & Mean & Range & Mean & Range & Mean & Range \\
\hline Lipid (\%) & 1.9 & $0.9-3.5$ & 1.6 & $0.4-3.9$ & 1.8 & $0.4-3.9$ \\
\hline $\mathrm{p}, \mathrm{p}^{\prime}-\mathrm{DDE}$ & 329 & $38.8-1183$ & 655 & $69.3-5547$ & 492 & $38.8-5547$ \\
\hline p,p'- DDD & 37.3 & $2.2-132$ & 36.4 & $6.0-318$ & 36.9 & $2.2-318$ \\
\hline $\mathrm{p}, \mathrm{p}^{\prime}-\mathrm{DDT}$ & 22.3 & $4.0-55.6$ & 22.5 & $4.7-89.9$ & 22.4 & $4.0-89.9$ \\
\hline DDTs & 389 & $75-1198$ & 714 & $75-5683$ & 553 & $75-5683$ \\
\hline$\alpha-\mathrm{HCH}$ & 9.7 & $<$ LOD -30.2 & 3.8 & $<$ LOD -18.5 & 6.8 & $<$ LOD . 30.2 \\
\hline$-\mathrm{HCH}$ & 3.6 & $1.1-6.3$ & 4.1 & $<$ LOD -29.2 & 3.9 & $<$ LOD -29.2 \\
\hline$-\mathrm{HCH}$ & 12.0 & $1.2-24.1$ & 3.1 & $<$ LOD -14.8 & 7.6 & $<$ LOD -24.1 \\
\hline $\mathrm{HCHs}$ & 25.3 & $3.5-57.8$ & 11.0 & $<$ LOD -62.5 & 18.3 & $<$ LOD -62.5 \\
\hline PCB 28 & 0.2 & $<$ LOD -0.9 & 0.7 & $<\mathrm{LOD}-3.0$ & 0.5 & $<\mathrm{LOD}-3.0$ \\
\hline PCB 52 & 0.3 & $<$ LOD -3.3 & 2.3 & $<$ LOD - 11.7 & 1.3 & $<$ LOD - 11.7 \\
\hline PCB 101 & $<$ LOD & $<$ LOD & 0.5 & $<\mathrm{LOD}-2.3$ & 0.3 & $<\mathrm{LOD}-2.3$ \\
\hline PCB 118 & 1.0 & $<\mathrm{LOD}-3.1$ & 2.3 & $<\mathrm{LOD}-6.3$ & 1.7 & $<\mathrm{LOD}-6.3$ \\
\hline PCB 153 & 2.7 & $1.5-4.8$ & 3.7 & $1.2-16.8$ & 3.2 & $1.2-16.8$ \\
\hline PCB 138 & 2.3 & $0.5-5.1$ & 2.6 & $0.6-12.1$ & 2.5 & $0.5-12.1$ \\
\hline PCB 180 & 3.6 & $1.5-7.7$ & 4.5 & $1.4-16.7$ & 4.1 & $1.4-16.7$ \\
\hline PCBs & 10.1 & $4.8-15.8$ & 16.5 & $5.6-67.9$ & 13.3 & $4.8-67.9$ \\
\hline
\end{tabular}

${ }^{(*)}$ LOD for each chemical and n.d. as in Table 1.

For DDTs: The isomers of DDT were found in all breast milk samples in 2010 and 2011; their levels in the samples in 2011 were in larger range and higher than that in 2010 (p < 0.05 ); these levels of DDTs were much lower than that in Hanoi city $(2100$ ng/g lipid, $n=42)$ and Hochiminh city (Minh N.H., 2004).

For HCHs: The isomers of $\mathrm{HCH}$ were detected in all samples in 2010 and in above $50 \%$ of total samples in 2011; it was differnent from DDTs, the levels of HCHs in 2010 were in larger range and higher than that in $2011(\mathrm{p}<0.05)$.

For PCBs: The levels of PCBs congeners found in 2010 were in lager range and higher than that in $2011(\mathrm{p}<0.05)$; while only congener PCB 180 was detected in all samples in 2010, three congeners (PCB 153, PCB 138 and PCB 180) were found in all sample in 2011; the other congeners of PCBs were detected in fewer samples and at lower levels.

The data of OCPs and PCBs found in Hue city (this study) were compared with that in Hanoi and Hochiminh cities (Minh N.H., 2004) as indicated in Figure 1.

For assessing health risk for breast fed babies, estimated daily intake (EDI) of the pollutants (OCPs and PCBs) by babies was estimated and then compared with tolerable daily intake (TDI) according to the guideline of Canada Health Agency (Oostdam, 1999). The EDI was calculated according to fomulas (1), accepting that weight of each baby was $5 \mathrm{~kg}$ on average and each baby consumed $700 \mathrm{~g}$ breast milk per day (Oostdam, 1999; Minh N. H., 2004; Sudaryanto A., 2006):

$$
\mathrm{EDI}=\frac{\mathrm{C}_{\text {milk }} \times 700 \mathrm{~g} \mathrm{x}_{\text {lipid }}}{5 \mathrm{~kg}}
$$

EDI: estimated daily intake (g/kg wt/day)

$\mathrm{C}_{\text {milk: }}$ : content of pollutans in breast milk ( $\mathrm{g} / \mathrm{g}$ lipid)

$\mathrm{C}_{\text {lipid }}$ : content of lipid in breast milk (\%)

The data of average EDIs of OCPs and PCBs for breast fed babies in the study areas showed in Table 3 were rather lower than the TDIs.

Table 3. EDIs ( $\mathrm{g} / \mathrm{kg} w \mathrm{w} /$ day) of DDTs, HCHs and PCBs for breast fed babies in Hue city in 2010 and 2011.

\begin{tabular}{|c|c|c|c|c|c|c|}
\hline & \multicolumn{2}{|l|}{ DDTs } & \multicolumn{2}{|l|}{ HCHs } & \multicolumn{2}{|l|}{ PCBs } \\
\hline & Mean & Range & Mean & Range & Mean & Range \\
\hline Thuy Xuan $(n=13)$ & 0.20 & $0.01-0.38$ & 0.17 & $0.05-0.33$ & 0.17 & $0.001-0.21$ \\
\hline Huong Long $(\mathrm{n}=13)$ & 0.27 & $0.05-0.72$ & 0.25 & $0.03-0.62$ & 0.14 & $0.003-0.25$ \\
\hline Thuy Duong $(n=14)$ & 0.26 & $0.09-0.51$ & 0.23 & $0.11-0.74$ & 0.25 & $0.02-0.43$ \\
\hline Thuy Bieu $(n=14)$ & 1.01 & $0.17-2.78$ & 0.06 & 0.01 & 0.03 & $0.01-0.05$ \\
\hline An Cuu $(n=14)$ & 0.89 & $0.14-3.15$ & 0.02 & $0-0.04$ & 0.03 & $0.01-0.06$ \\
\hline $\mathrm{TDI}^{(*)}$ & 20 & & 0.3 & & 1.0 & \\
\hline
\end{tabular}

${ }^{(*)} \mathrm{TDI}$ (g/kg wt/day) according to Canada guideline (Oostdam, 1999).

\section{Conclusion}

Although OCPs were prohibited for agricultural use since 1995 and transform oils containing PCBs were collected and controled in Vietnam, the pollutants were detected in most of human breast milk samples collected from lactating mothers in the suburbs of Hue city in 2010 and 2011. Generally, the levels of DDTs was higher than the levels of HCHs and PCBs in the samples. In spite of that, the EDIs of the pollutants indicated that there was not much concern about 
the health risk for breast fed babies in the area under study.

\section{References}

[1] Ennaceur S., Gandoura N., Driss M. R., 2008. Distribution of polychlorinated biphenyls and organochlorine pesticides in human breast milk from various locations in Tunisia: Levels of contamination, influencing factors, and infant risk assessment, Environmental Research, 108, 86 - 93.

[2] Minh N. H., Someya M., Minh T. B., Kunisue T., Iwata H., Watanabe M.,Tanabe S., Viet P. H., Tuyen B. C., 2004. Persistent organochlorine residues in human breast milk from Hanoi and Hochiminh city, Vietnam: contamination, accumulation kinetics and risk assessment for infants, Environmental Pollution,129, 431 - 441.

[3] Raab U., Preiss U., Albrecht M., Shahin N., Parlar H., Fromme H., 2008. Concentrations of polybrominated diphenyl ethers, organochlorine compounds and nitro musks in mother's milk from Germany (Bavaria), Chemosphere, 72, 87 $-94$.

[4] Sudaryanto A., Kunisue T., Kajiwara N., Iwata H., Adibroto T. A., Hartono P., Tanabe S., 2006. Specific accumulation of organochlorines in human breast milk from Indonesia: Level, distribution, accumulation kinetics and infant health risk, Environmental Pollution, 139, 107 - 117.

[5] Polder A., Skaare J. U., Skjerve E., Loken K. B., Eggesbo M., 2009. Levels of chlorine pesticides and polychlorinated biphenyls in Norwegian breast milk (2002-2006), and factors that may predict the level of contamination, Science of the Total Environment, 407, 4584 - 4590.

[6] Beyer A., Biziuk M. (2010). Comparison of efficiency of different sorbents used during clean-up of extracts for determination of polychlorinated biphenyls and pesticide residues in low-fat food, Food Research International, 43, pp. $831-837$

[7] Devanathan G., Subramanian A., Someya M., Sudaryanto A., Isobe T., Takahashi S., Chakraborty P., Tanabe S. (2009). Persistent organochlorines in human breast milk from major metropolitan cities in India, Environmental Pollution, 157, pp. $148-154$.

[8] Ntow W. J., Tagoe L. M., Drechsel P., Klederman P., Gijzen H. J., Nyarko E. (2008). Accumulation of persistent organochlorine contaminants in milk and serum of farmers from Ghana, Environmental Research, 106, pp. 17 - 26.

[9] Wang Y. R., Zhang M., Wang Q., Yang D. Y., Li C.L., Liu J., Li J. G., Li H., Yang X. Y. (2008). Exposure of mother-child and postpartum woman-infant pairs to DDT and its metabolites in Tianjin, China, Science of the Total Environment, 396, pp. 34 - 41.

[10] Kunisue T., Muraoka M., Ohtake M., Sudaryanto A., Minh N. H., Ueno D., Higaki Y., Ochi M., Tsydenova O., KamiKawa S., Tonegi T., Nakamura Y., Shimomura H., Nagayama J., Tanabe S. (2006). Contamination status of persistent organochlorines in human breast milk from Japan: Recent levels and temporal trend, Chemosphere, 64, pp. 1601 - 1608. 